\title{
Catechins green tea upregulates the expression of ABCA1, ABCG1, and SRB1 in rats induced atherogenic diet
}

\author{
Erna Susanti ${ }^{*}$, Retty Ratnawati ${ }^{2}$, Aulanni'am Aulanni'am², Achmad Rudijanto ${ }^{2}$ \\ ${ }^{1}$ Academy of Pharmacy and Food Analyst, Putra Indonesia Malang, Malang, Indonesia. \\ ${ }^{2}$ Lecturer on Doctoral Program Biomedical Science, Medical Faculty, Brawijaya University, Malang, Indonesia.
}

\section{ARTICLE INFO \\ Received on: 26/01/2018 \\ Accepted on: 29/10/2018 \\ Available online: 30/03/2019}

\section{Key words:}

Catechins, reverse cholesterol transport, atherogenesis, ABCA1, ABCG1, SRB1.

\begin{abstract}
The efflux of cholesterol from macrophage to liver is known as reverse cholesterol transport (RCT). Impaired cholesterol efflux leads to cholesterol accumulation in macrophages. Therefore, how to increasing cholesterol efflux may be an effective strategy for atherosclerosis prevention. Key molecules that play a vital role in the efflux of cholesterol from macrophage are Adenosin Tri Phosphate (ATP)-binding casette transporters A1 and G. This study was undertaken to clarify the effect of Catechins on the expression of specific transporters such as ATP-binding cassette sub-family A member 1 (ABCA1), ATP-binding cassette sub-family G member 1 (ABCG1) from macrophage to liver, and scavenger receptor class B type I (SRB1). This research was done on Wistar rats induced atherogenic diets. SRB1 is one of the transporters to facilitate the delivery of cholesterol from the macrophage to the liver. The SRB1 pathway mediated the selective uptake of cholesteryl ester. Catechins significantly increased the mRNA expression of ABCA1 and ABCG1 in aorta as well as SRB1 of liver also increased. Thus, Catechins decreased the total cholesterol levels in aorta and serum. Catechins can be developed as a potential agent to increase ABCA1 to inhibit atherogenesis process. In conclusion, this study indicates that the potential anti-atherogenic properties of Catechins could be explained, at least in part, as being due to upregulated expression of ABCA1, ABCG1, and SRB1 through activation liver X receptor signaling pathway.
\end{abstract}

\section{INTRODUCTION}

Liver $\mathrm{X}$ receptor (LXR) is one of the signaling pathway that contributes to the inhibition of atherogenesis via reverse cholesterol transport (RCT) mechanism. LXR that stimulate efflux of cholesterol from cells to high-density lipoprotein (HDL) particle may protect cholesterol overload through increased expression of the target gene associated with RCT, the conversion of cholesterol into bile acids, and intestinal cholesterol transport. HDL particle mediated cellular cholesterol efflux. The target genes associated with RCT include the following groups: Adenosin Tri Phosphate (ATP)-binding cassette [(ABC) sub-family A member 1 (A1)/ sub-family G member 1 (G1)/sub-family G member 1 (G5)/subfamily G member 1 (G8)], phospholipid transport protein Apo E/ $\mathrm{CI} / \mathrm{CII} / \mathrm{CIV}$, and cholesterol $7 \alpha$-hydroxylase (Cyp 7a). LXR also

\section{${ }^{*}$ Corresponding Author}

Erna Susanti, Academy of Pharmacy and Food Analyst, Putra Indonesia Malang, Malang, Indonesia.E-mail:rna_far@yahoo.co.id triggers the synthesis of fatty acids (FA) and triglycerides through upregulation of genes using sterol regulatory element binding protein 1c, FA synthase, and acetyl-CoA carboxylase (Annema and Tietge, 2012).

Recently, the studies dealing with RCT is increasing significantly. The study of cholesterol efflux by Catechins treatment was carried out by Rosenblat et al. (2008). The results of the study show that the extra virgin olive oil enriched with polypheenols green tea increase the cholesterol efflux through HDL increase. This research is unable to explain the role of mechanisms in the cholesterol efflux (Chang et al., 2012).

As an LXR agonist, Catechins' activity can be observed by measuring parameters associated with the activation of LXR signaling pathways. LXR signaling is activated by an agonist effect on the cholesterol efflux in macrophages through ABCA1, ATPbinding cassette sub-family $\mathrm{G}$ member 1 (ABCG1), and scavenger receptor class B type I (SRB1). Proteins are main transporter that plays a vital role in cholesterol efflux. ABCA1 and ABCG1 transporters are widely expressed in macrophages and is also 
Table 1. Composition of normal and atherogenic diets.

\begin{tabular}{lcc}
\hline Component & Normal diet & Atherogenic diet \\
\hline PARS/chicken feed $(\mathrm{g})$ & 225 & 200 \\
Wheat flour $(\mathrm{g})$ & 100 & 100 \\
Cholesterol $(\mathrm{g})$ & - & 8 \\
Cholic acid $(\mathrm{g})$ & - & 0.8 \\
Pig oil $(\mathrm{ml})$ & - & 10 \\
Aquadest $(\mathrm{ml})$ & 100 & 81.2 \\
\hline
\end{tabular}

Note: Chicken feed/PARS (with water content, proteins, fats, fiber, ash, calcium, phosphorus, antibiotics, and coccidiostat).

expressed on hepatocytes, enterocytes, adipocytes, and skeletal muscle cells. ABCA1 is a major protein for the efflux of cholesterol selluler to apolipoprotein A1 (ApoA1) and be the first step in RCT. ABCA1 is also a full transporter that works as a single molecule to transfer cholesterol and phospholipids of the plasma membrane to pre-HDL and lipid-free ApoA1. Whereas ABCG1 transfer only cholesterol to HDL (4). Therapeutic interventions to increase the expression of $\mathrm{ABCA} 1$ and $\mathrm{ABCG} 1$ are an effective strategy to increase RCT macrophages and potentially reducing atherosclerosis. Other parameters that play a vital role in RCT is SRB1.

$\mathrm{SRB} 1$ is a receptor responsible for the uptake of cholesterol ester (CE) from HDL to the liver, hepatic SRB1 is also known as positive regulator of macrophage RCT. Without the SRB1, macrophages RCT will not run. While SRB1 hepatic overexpression increase the cholesterol excretion into feces. The role of SRB1 in the uptake of cholesterol in the liver and the effect of RCT was described by Zhang et al. (2005). Other studies (El Bouhassani et al., 2011; Zhao et al., 2011) show the results of the same study that mice with knockout SRB1 will reduce RCT. Hence, the SRB1 plays a vital role in RCT through the uptake of cholesterol by the liver. Catechins from green tea GMB-4 Clone can be developed agonist LXR. So, further research is needed to prove the effect of Catechins on the inhibition of the atherogenesis process through activation LXR signaling (El Bouhassani et al., 2011; Hu et al., 2010; Hosomi et al., 2010).

\section{MATERIALS AND METHODS}

\section{Materials}

Green tea GMB-4 Clone were obtained from Tea and Quinine Research Center Gambung. Catechins were obtained from the isolation of green tea GMB-4 clones in powder form. The isolation procedure was conducted on the Laboratory of Chemistry, Faculty of Science, Bandung Institute of Technology, Bandung, Indonesia. Reagent grade of all chemicals were used.

\section{Animal care and experimental desain}

In this study, 25 experimental animals were used and these were divided into five treatment groups at the time when the study was 8 weeks. Five-week-old male Wistar rats were well-kept placed in room temperature. After acclimatization for 7 days have given a normal diet, the groups of treatment have given atherogenic diets prepared according to that recommended by Murwani et al. (2006). Animals were acclimatized pretreatment to adapt the environmental conditions. Five groups of rats were given free access to water and experimental diets. Table 1 shows the composition of the experimental diet atherogenic.
Experimental diet consumption were recorded every day whereas BW were recorded every week. After treatment for 8 weeks, rats were weighted and sacrificed. Blood, liver, and aortic tissue were collected, rinsed and kept at $-80^{\circ} \mathrm{C}$ until analysis. The experimental protocol was reviewed and approved by the Ethics Committee of Medical Faculty of Brawijaya University.

\section{Real-time PCR mRNA analysis}

To analysis mRNA, a volume of $30 \mathrm{mg}$ of frozen aortic or hepatic tissuewas used. Isolation RNA was performed by RNeasy Mini Kit. The A260/A280 ratio of the samples ranged from 1.8 to 2.2. Real-time PCR assays were carried out using SYBR Green PCR Master Mix. The results were normalized to GAPDH (housekeeping gene) expression (Julve et al., 2011; Kouadjo et al., 2007; Lizuka et al., 2012).

\section{Western blot analysis}

The Western blot analysis was used to identify ABCG1, ABCA1, and SRB1 expression. The liver and aorta tissues were homogenized in lysis buffer and briefly sonicated. Lysis buffer is composed of $50 \mathrm{mmol} / \mathrm{l}$ Tris- $\mathrm{HCl}, 1 \mathrm{mmol} / \mathrm{l}$ ethylenediaminetetraacetic acid, $1 \%$ Triton X-100, $0.1 \mathrm{mg} / \mathrm{ml}$ phenylmethylsulfonyl fluoride (a protease inhibitor that reacts with serine residues to inhibit trypsin, chymotrypsin, thrombin and papain), $1 \mathrm{~g} / \mathrm{ml}$ aprotinin, $10 \mathrm{~g} / \mathrm{ml}$ leupetin, and $\mathrm{pH}$ 7.4. Samples (50 g/lane) were subjected to SDS-PAGE and transferred to nitrocellulose membranes. Blots were placed in Tris-buffered saline, $0.05 \%$ Tween 20 (TBST) supplemented with PBS containing 3\% bovine serum albumin for 2 hours at room temperature and then incubated overnight at $4{ }^{\circ} \mathrm{C}$. The blots were washed three times with TBST, and the membranes were incubated with horseradish peroxidase-conjugated antibodies for 1 hour at room temperature and washed again as described previously (Julve et al., 2011; Kouadjo et al., 2007; Lizuka et al., 2012).

\section{Aortic and hepatic tissue cholesterol content quantification}

A volume of $10 \mathrm{mg}$ of aortic and hepatic tissue were homogenized and the lipid content was extracted by treatment with chloroform and Triton X-100 followed by centrifugation. The lower phase was collected and vacuum dried. Therefore, the results of drying were dissolved in cholesterol reaction buffer by vortexing for 5 minutes and observed via a Cholesterol Assay Kit (Abnova) using absorbance spectrophotometry according to the manufacturer's details (Julve et al., 2011; Kouadjo et al., 2007; Lizuka et al., 2012).

\section{Statistical analysis}

Quantitative data of ABCA1, ABCG1, and SRB1 expression were obtained. Mean and SD were determined. Analysis of variance (ANOVA) was done to measure statistical differences between multiple groups. Statistical comparisons were made using Tukey test. $p<0.05$ was considered statistically significant.

\section{RESULTS AND DISCUSSION}

\section{Growth parameters and energy intake}

Initial BW of the rat was not significantly different pretreatment. After Catechin administration, BW of the rat that had 
Table 2. Initial BW, final BW, BW gain, energy intake of rat fed normal, atherogenic diet and treatment of three doses catechin.

\begin{tabular}{|c|c|c|c|c|c|}
\hline & Positive control & Negative control & Dose I & Dose II & Dose III \\
\hline Initial BW (g) & $152.46 \pm 3.61$ & $161.64 \pm 4.09$ & $163.98 \pm 6.43$ & $161.3 \pm 8.556$ & $154.72 \pm 0.99$ \\
\hline Final BW (g) & $195.74 \pm 15.09$ & $272.82 \pm 11.18$ & $240.86 \pm 19.25$ & $247.22 \pm 35.65$ & $238.08 \pm 25.77$ \\
\hline BW gain (g) & 43.28 & 111.18 & 76.88 & 85.92 & 83.36 \\
\hline Energy intake (kcal/day) & $\begin{array}{c}3.43 \mathrm{cal} \times 24.82= \\
85.14 \mathrm{cal} / \text { day }\end{array}$ & $\begin{array}{c}4.03 \mathrm{cal} \times 23.33= \\
94.03 \mathrm{cal} / \text { day }\end{array}$ & $\begin{array}{c}4.03 \mathrm{cal} \times 23.19= \\
93.47 \mathrm{cal} / \text { day }\end{array}$ & $\begin{array}{c}4.03 \mathrm{cal} \times 22.99= \\
92.67 \mathrm{cal} / \text { day }\end{array}$ & $\begin{array}{c}4.03 \mathrm{cal} \times 23.68= \\
95.44 \mathrm{cal} / \text { day }\end{array}$ \\
\hline
\end{tabular}

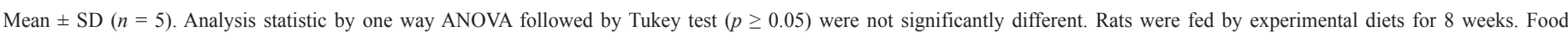
consumption was recorded every day and BW was measured every week. Source: Bewick et al., 2004.

normal diet was significantly declined by three doses when compared with the rat that had atherogenic diets. On contrary, Catechins had not gave significant effect to energy intake for rat (Table 2).

\section{mRNA expression level}

Melting peaks determine the specificity of primers. One peak was shown at melting curve (Fig. 1a-c). Figure 1 shows the amplification curve of standard, mRNA ABCA1, ABCG1, and SRB1. Difference in crossing point (CP) value shows the difference in quantification. When the $\mathrm{CP}$ value smaller, then the quantification of mRNA will be greater. Quantification results of mRNAABCA1, ABCG1, and SRB1 are shown in Table 3. Figure 1 shows the results of melting peaks from Real time polymerase chain reaction(RT-PCR) analysis.

The quantitative mRNA is based on the standard of GAPDH with various concentrations. Relative quantification of samples was determined by the standard curve. To homogenize the number of samples, the levels of RNA were determined and was isolated by using nanodrop with $100 \mathrm{ng}$ per sample.

Catechins $30 \mathrm{mg} / \mathrm{kg} \mathrm{BW}$ shows an increase in the expression of mRNA ABCA1, ABCG1 of aorta, and SRB1 of liver. This result indicated that the macrophage cholesterol efflux mediated ABCA1 and ABCG1, whereas cholesterol was uptaken by the liver via SRB1. Statistical analysis showed that mRNA, ABCA1, and ABCG1 between treatment groups was significantly different. While mRNA and SRB1 of dose II and III groups was significantly different from atherogenic diet with $p=$ 0.036. Catechins of dosage $30 \mathrm{mg} / \mathrm{kg} \mathrm{BW}$ (body weight) was the optimum dose because it significantly increased the amount of mRNA, ABCA1, ABCG1, and SRB1 expression.

\section{Western blott analysis}

Western blot analysis was used to identify ABCA1, ABCG1, and SRB1 expression, as shown in Figure 2.

\section{Serum and aortic cholesterol parameters}

Total serum cholesterol levels from rats that had atherogenic diet was higher than rats that had normal diet. The total serum cholesterol levels from three doses of Catechins groups was significantly lower than atherogenic diet. Although free cholesterol levels showed similiar tendency like the total cholesterol level, Catechins groups were significantly lower than atherogenic diet groups. Dose II and dose III of Catechins showed decrease of total cholesterol in aorta from the rat that had atherogenic diet.

The aim of the experiment was to prove the effect of Catechins on the inhibition of atherosclerosis in vivo in rat that had atheregonic diet for 8 weeks. Murwani et al. (2006) show that the administration of rats' atherogenic diet (Rattus novergicus Wistar strain) for 8 weeks can raise blood cholesterol levels and can induce the formation of foam cells significantly (Maitra and Li, 2013). The results showed significant difference in final BW among the groups, but energy intake was not significantly different. This results indicated that final BW was not effected by energy intake, but it was influenced by Catechins treatment in various doses.

mRNA analysis for this research used RT-PCR with $\beta$-actin as housekeeping genes. Expressions of $\beta$-actin were detected in all tissues to maintain cellular functions. The expressions were needed for normal cellular physiology. Quantitative gene expression should be normalized with the expression of housekeeping gene. The use of this housekeeping gene expression was fixed and not affected by the treatment. This expression was not affected by cell development, disease, and treatments (Burke et al., 2010). Results of RT-PCR analysis showed an increase in mRNA, ABCA1, ABCG1 of the aorta and SRB1 of the liver by Catechins treatment. The significant difference was shown in all doses for mRNA and ABCA1 whereas mRNA, ABCG1, and SRB1 was significantly different in dose $30 \mathrm{mg} / \mathrm{kg} \mathrm{BW}$ and 120 $\mathrm{mg} / \mathrm{kg} \mathrm{BW}$. Optimum dose $30 \mathrm{mg} / \mathrm{kg}$ BW because it provided a significant increase in the mRNA of ABCA1, ABCG1, and SRB1.

Atherogenesis process can be inhibited by a RCT mechanism in which cholesterol will be effluxed from macrophage to the liver, therefore foam cells will not be generated (Cimmino et al., 2009). On macrophages, cholesterol uptake was mediated by the Scavenger receptor A and cluster of differentiation 36 whereas cholesterol efflux is mediated by ABCA1, ABCG1, and SRB1 (Meyer et al., 2013). ABCA1- and ABCG1-mediated flux are unidirectional, leading to net removal of cell cholesterol. These efflux cholesterol from macrophage was needed different types of HDL as acceptor particles, the relative levels of acceptor particles play an important role in determining the efficiency of cholesterol efflux when cells are exposed to serum or isolated total HDL (Ogura et al., 2011).

SRB1 is responsible for a major portion of HDL cholesteryl ester uptake in liver. SRB1 is expressed in hepatocytes and macrophages mediate cholesterol efflux. SRB1-mediated selective cholesteryl ester uptake is a two-step process: first, "productive" binding of lipoprotein to the extracellular domain of SRB1 and second, selective delivery of cholesteryl ester into the cell mediated by its extracellular domain. Mice with a mutation in one or both alleles of SRB1 have a dose-dependent increase in plasma cholesterol levels, whereas ApoA1 levels are unchanged, consistent with a selective lipid uptake process (Rader et al., 2009). 


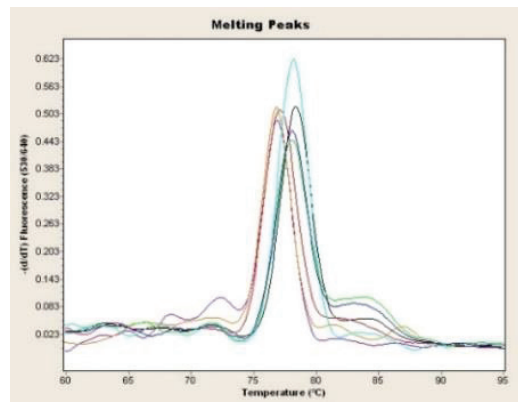

(a)

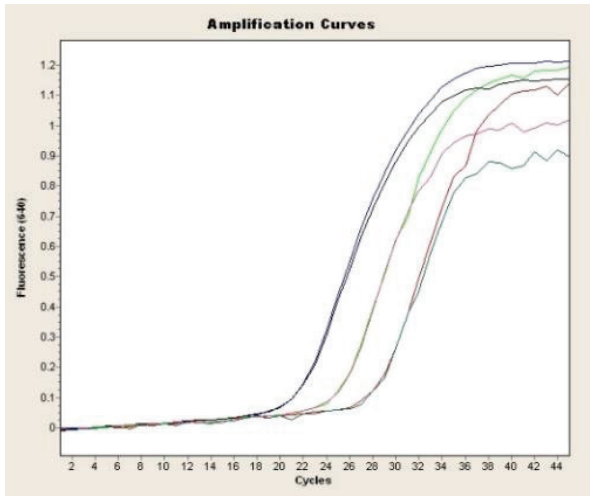

(d)

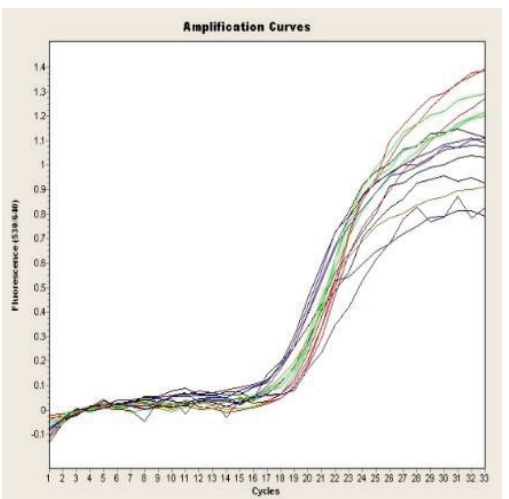

(f)

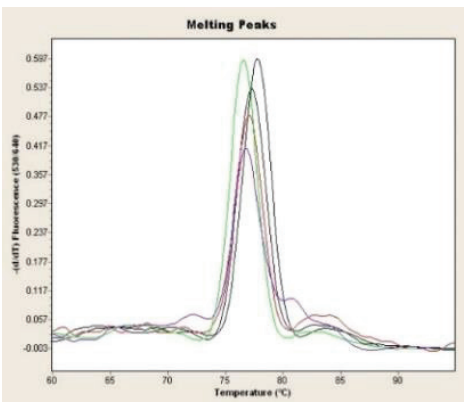

(b)

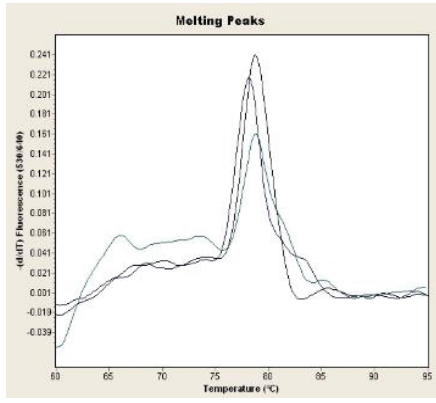

(c)

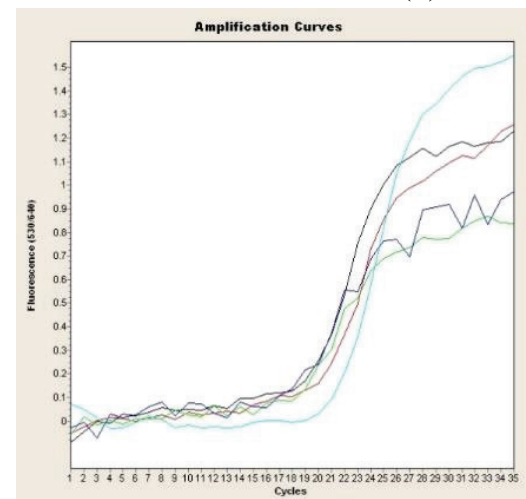

(e)

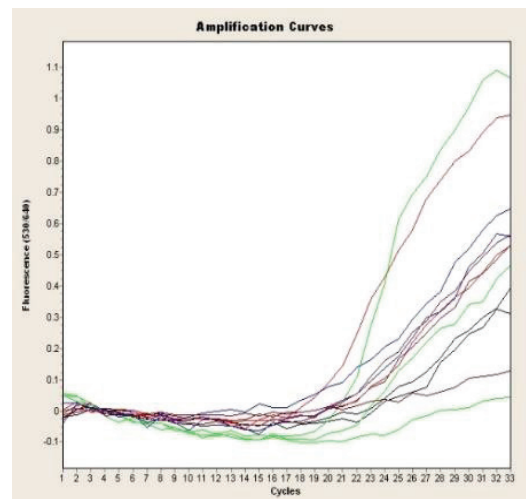

(g)

Figure 1. Melting peak of $\mathrm{ABCA} 1, \mathrm{ABCG} 1$, and $\mathrm{SRB} 1$ ( $\mathrm{a}, \mathrm{b}$, and $\mathrm{c}$ ) and amplification curve of standard, mRNA ABCA1, ABCG1, and SRB1 (d, e, f, and g).

Results of other studies indicate that it is not always cholesterol efflux mediated these transporter. Research by Zhang et al. (2010) stated that the efflux of cholesterol increased the levels of ABCA1 protein without affecting the expression of SRB1 and ABCG1. Inhibition of ABCA1 into the 4,4'-diisothiocyanatostilbene-2,2'-disulfonic acid disodium salt generate suppressive effect on lipid accumulation. Also, upregulation of $\mathrm{ABCA} 1$ is caused by a decrease in the rate of degradation of $\mathrm{ABCA} 1$ through increasing dephosphorylation ABCA1 by protein phosphatase $2 \mathrm{~B}$. Improved stability ABCA1 through dephosphorylation cause a decrease in the accumulation of cholesterol in macrophage foam cells. The process of degradation and stabilization of transporter proteins effect their expression (Rosenblat et al., 2008). Ogura et al. (2011) showed that the ubiquitin proteasome system (UPS) pathway mediates non-lysosomal degradation for ABCA1, ABCG1 affecting RCT in vivo. Specific inhibitors of the UPS can be used as novel therapies to improve the RCT (Uto-Kondo et al., 2014). UtoKondo et al. (2010) showed that the phenolic acids improve both the mRNA and protein levels in ABCG1 and SRB1 but not for ABCA1 mRNA because of the increased stability (Zhang et al., 2010).

Polyphenols remove cholesterol from macrophage through transporters. Cholesterol is effluxed out of macrophage foam cells in the first step of RCT. Efflux to lipid free or lipid-poor apolipoprotein A1 (apoA1) particles (which then become mature HDL) occurs via the ABCA1 transporter, whereas efflux directly to mature HDL particles occurs via the ABCG1 transporter 
Table 3. Quantification of mRNA ABCA1, ABCG1, and SRB1 by RT-PCR.

\begin{tabular}{lccc}
\hline Groups & mRNA ABCA1(cDNA copied) & mRNAABCG1(cDNA copied) & mRNA SRB1(cDNA copied) \\
\hline Control - & $280,871 \pm 59,799$ & $2,477,302 \pm 375,765$ & $3,001,581 \pm 605,417$ \\
Control + & $207,285 \pm 43,355$ & $1,701,568 \pm 57,907$ & $2,463,598 \pm 90,662$ \\
Dose I & $489,326 \pm 2,168$ & $1,344,520 \pm 6,592$ & $2,939,908 \pm 226,964$ \\
Dose II & $424,872 \pm 11,470$ & $3,128,278 \pm 6,592$ & $3,475,395 \pm 936,584$ \\
Dose III & $339,448 \pm 5,023$ & $3,422,272 \pm 391,851$ & $3,470,793 \pm 55,309$ \\
\hline
\end{tabular}

ABCA1 aorta 220kD

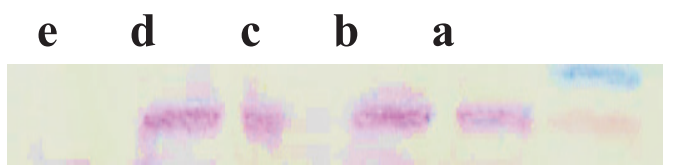

SRB1 hepar $82 \mathrm{kDa}$

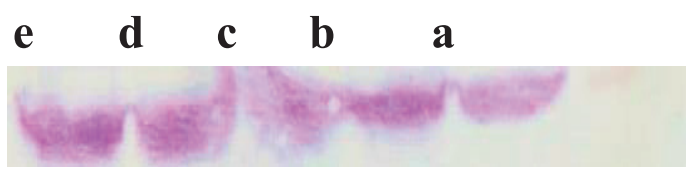

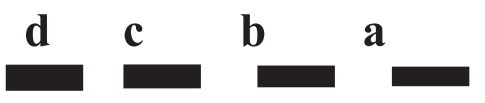

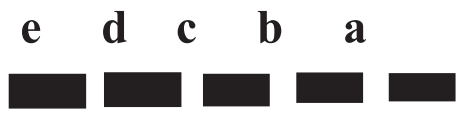

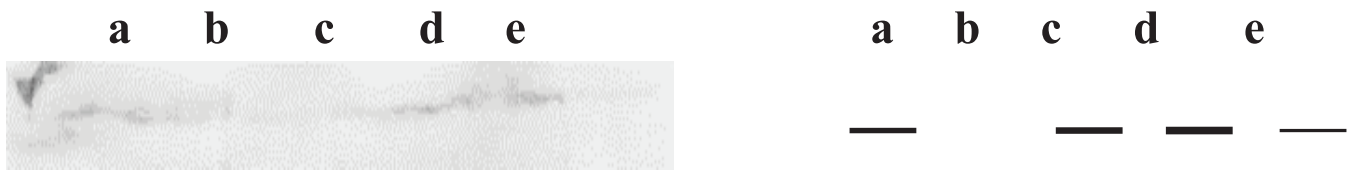

ABCG1 aorta 74 kDa

Figure 2. Western blot analysis of $\mathrm{ABCA} 1, \mathrm{ABCG} 1$, and SRB1 expression from aorta and hepar of rats. Note: (a) rats with normal diet; (b) rats with atherogenic diets; rats with atherogenic diets (c) Catechins dose I (d) Catechins dose II (e) Catechins dose III.

(Zhang et al., 2005). Resveratrol and anthocyanin, groups of flavonoid, increase cholesterol efflux through the upregulation of LXR. From the previous study that shown one of polyphenol, Paeonol enhanced the mRNA and protein expression of ABCA1 but did not alter the protein level of ABCG1 or other scavenger receptors. Given pharmacological inhibitor to inhibit activity of ABCA1 was related with small interfering RNA so negates the effect on cholesterol efflux. Increasing activity of ABCA1 was caused by increasing activity of $\operatorname{LXR} \alpha$ (Burke et al., 2010).

Catechins increase cholesterol efflux through increased mRNA ABCA1 at all doses, while increased mRNA ABCG1 and SRB1 at a dose of 30 and $120 \mathrm{mg} / \mathrm{kg} \mathrm{BW}$. The mechanism of the expression of ABCA1, ABCG1, and SRB1 is increased through interleukin-1 receptor-associated kinase 1 (IRAK1) and toll-interacting protein (Tollip). IRAK-1 and Tollip are suppressed by inhibiting the expression of nuclear receptors such as retinoic acid receptor $\alpha(\mathrm{RAR} \alpha)$ mediated by glycogen synthase kinase-3 $\beta$ (GSK3 $\beta$ ). Expression is influenced by the inhibition of nuclear receptors such as RAR $\alpha$-mediated GSK3 $\beta$. IRAK-M as an antagonist make IRAK-1 modulate SRB1 and efflux cholesterol from macrophage. Intracellular signaling role in the activation of GSK $3 \beta$ and suppression of nuclear receptors that affect the expression of ABCA1, ABCG1, and SRB1 (Zhang et al., 2005). Transforming growth factor (TGF)- $\beta 1$ is positively correlated with the expression of ABCA1, ABCG1, and SRB1 through increased expression of LXR. Recent research indicates the occurrence of crosstalk between TGF- $\beta 1$ with LXR signaling. There is a synergistic effect on the expression of target genes LXR and ABCA1. TGF- $\beta 1$ also can activate the mitogen activated protein kinases cascade that will effect downstream signaling (Zhao et al., 2012). Another mechanism of Catechins to enhance the expression of ABCA1 is through activation of TGF $\beta$ activated kinase 1 (TAK1) and mitogen-activated kinase kinase 3/6 (MKK3/6). TAK1 signaling and MKK3/6 activate p38 by stimulating the phosphorylation p38. Activated p38 further enhances binding specificity protein (SP1) with LXR $\alpha$ to the promoter ABCA1 which will increase the expression of ABCA1 (Zhao et al., 2011).

According Wojcicka et al. (2007), there is the influence of the CoR (co-repressor) and CoA (co-activator) of the regulation of gene transcription heterodimer LXR/ retinoid X receptors (RXR). Bond LXR agonist stimulation induces transcription by recruiting CoA or through induced dissociation CoR. LXR also affect the expression of mRNA and expression of transporter proteins that play a role in cholesterol efflux. The presence of peroxisome proliferator activated receptor (PPAR) $\alpha$ and PPAR $\gamma$ agonists increase the expression of LXR. PPAR $\gamma$ affect cholesterol efflux through transcriptional pathways involving $\operatorname{LXR} \alpha$ and $\mathrm{ABCA} 1 . \mathrm{LXR} \alpha$ gene is the target gene of PPAR $\gamma$ whereas ABCA1 is a target of LXR $\alpha$. Regulation of PPAR $\gamma$ and LXR $\alpha$ stimulated expression of ABCA1 and cholesterol efflux from macrophages (Chawla et al., 2001). 
Co-activator that required transactivation of $\mathrm{LXR} \alpha$ is Grip 1, Ap 160 co-activator, thyroid hormone receptor-associated protein, and PPAR gamma coactivator- $1 \alpha$ (PGC- $1 \alpha)$. PGC- $1 \alpha$ acts not only as a key regulator of hepatic gluconeogenesis but also as co-activator LXR $\alpha$. In the absence of ligand, nuclear receptor represses gene transcription by recruiting co-repressor proteins such as nuclear receptor co-repressor (NCoR) and silencing mediator of retinoic acid and thyroid hormone receptor (SMRT). Transrepression by LXR is dependent on the interaction of NCoR and SMRT (Geyereger et al., 2006).

ABCA1 gene promotor occupied by activator upstream stimulatory factor (USF) 1 and USF2 will recruit co-activator with histone acetiltransferase activity and the concentration is enough to stimulate promoter activity. Role of histone acetylation is modifying histone on the regulatory gene regions and facilitate the recruitment of other protein required for gene transcription. In the absence of LXR agonists, NCoR recruitment was needed to maintain the ABCA1 gene in basal conditions. Macrophages with $\mathrm{LXR}^{-1-}$, NCoR not recruited by promoters ABCA1, causing ABCA1 repression gene (Wagner, 2003). LXR was an important regulator in HDL metabolism because of their ability to control the expression of genes involved in RCT (Calkin and Tontonoz, 2010). Genetic defects of ABCA1 in tangier diseases will decrease HDL levels significantly.

ABCA1 mRNA macrophages is increased through the mechanism of the increased activity of DNA-binding SP1. SP1 regulates the conditions of basal and inducible transcription of several genes by binding to GC boxes (GGGCGG), GT motifs, or elements of cholesterol total in the promoter region of target gene. Promoter ABCA1 mouse consist of $1 \mathrm{GC}$ box located at 99 nucleotides upstream which is the start of transcription. SP1 mutations reduce the activity of the transcription of ABCA1 promoter. SP1 DNA-binding inhibition by mithramycin A suppresses the expression of ABCA1. Increased phosphorylation SP1 on macrophages increases and the DNA-binding activity of transcription factors also increases (Chen, 2011).

ABCA1 mRNA induced by the activation of LXR signaling through PPAR $\gamma-\mathrm{LXR}-\mathrm{ABCA} 1$ signaling pathway. $\mathrm{LXR} \alpha$ is the target PPAR $\gamma$, upregulation ApoE, and transporter ABCA1 and ABCG1. PPAR $\gamma$ ligands can activate PPAR $\gamma$ which have an effect on LXR $\alpha$. One of the natural PPAR $\gamma$ ligands are unsaturated FAs, oleic acid, linoleic acid, eicosapentaenoate, arachidonic acid, and prostanoid ( $\delta 15$-deoxy-12, 14-prostaglandin J2) (Chawla, 2001; Ferre, 2003). LXR agonists endogenous, result of lipid metabolism, may affect mRNA ABCA1 but both agonists PPAR $\gamma$ and LXR endogenous of this study is controlled by the positive control group-induced atherogenic diet. The results showed differences in mRNA between groups were given treatment Catechins with group induced atherogenic diet. So, it can be concluded that Catechins increase ABCA1 mRNA through activation of LXR signaling. Promoter LXR is a direct target heterodimer PPAR $\gamma / \mathrm{RXR}$ so agonists RXR can activate LXR, but in this study there was no ligand RXR that role, so that an increase in mRNA ABCA1 is not because of agonist RXR but because of the treatment Catechins as an agonist LXR. mRNA levels do not always correlate with protein levels because there is a mechanism of post-transcriptional and post-translational effect. But research by $\mathrm{Su}$ et al. (2015) shows that the relationship between ABCA1 mRNA with rate of cholesterol efflux with Pearson correlation 0.384 includes moderate correlation. Other studies supporting the relationship of mRNA expression with cholesterol efflux are Lizuka et al. (2012); Palozza et al. (2011); Voloshyna and Haio (2013); Zhao et al. (2012), on cholesterol efflux through some natural antioxidants and ABCA1 expression. LXR is a nuclear receptor while Catechins are polar substance and hydrophilic. The fact that how Catechins can penetrate through cell membrane lipid bilayer is described in the research by Starp et al. (2006). This study showed that the $(+)$ - catechin and $(-)$ - epicatechin are transported through the membrane via the dominant transport system of free diffusion and facilitated diffusion mediated by carrier.

Total serum cholesterol level is decreased by administering three doses Catechins whereas total cholesterol aorta is decreased in 30 and $120 \mathrm{mg} / \mathrm{kg} \mathrm{BW}$ dosage. Total cholesterol levels in the aorta are affected by the influx of cholesterol in macrophages; this is accomplished by the enzyme acyl-CoA cholesterol acyl transferase and cholesterol efflux process. The process is described as follows: lipoprotein that binds to $\mathrm{CE}$ influx to macrophages via receptor-mediated endocytosis, is further transported to the lysosome where CE hydrolyzed. Cholesterol flux was dissociated into the cytoplasm where partially cholesterol is excreted immediately (Brown, 1980).

\section{CONCLUSION}

Cathechins significantly increased the expression of ABCA1, ABCG1, and SRB1. Catechins treatment decreased the aortic cholesterol content and increased the cholesterol efflux. Moreover, LXR was upregulated by Catechins treatment. These results provide that Catechins-upregulated expressions of ABCA1, ABCG1, and SRB1 through LXR signaling pathway in rats induced aterogenic diet.

\section{ACKNOWLEDGMENTS}

The authors would like to thank the scholarship from The Directorate of General Higher Education, Ministry of Education and Culture of Indonesia.

\section{REFERENCES}

Annema W, Tietge UJV. Regulation of reverse cholesterol transport - a comprehensive appraisal of available animal studies. Nutr Metab, 2012; 9:25.

Bewick V, Cheek L, Ball J. Review statistics review 9: one-way analysis of variance. Crit Care, 2004; 8(2):130-6.

Brown MS, Goldstein JL. Lipoprotein receptors in the liver. Control signals for plasma cholesterol traffic. J Clin Invest, 1983; 72:743-7.

Burke MF, Khera AV, Rader DJ. Polyphenols and cholesterol efflux Is coffee the next red wine? Circ Res, 2010; 106:627-66.

Calkin A, Tontonoz P. LXR signaling pathway and atherosclerosis. Arterioscler Thromb Vasc Biol, 2010; 30:1513-8.

Chen M, Li W, Wang N, Zhu Yi, Wang X. ROS and NF-kB but not LXR mediate IL- $1 \alpha$ signaling for the downregulation of ATP-binding cassette transporter A1. Am J Physiol Cell Physiol, 2011; 292:C1493-501.

Chang YC, Lee TS, Chiang AN. Quercetin enhances ABCA1 expression and cholesterol efflux through a p38-dependent pathway in macrophages. J Lipid Res, 2012; 53(9):1840-50.

Chawla A, Boisvert WA, Lee CH, Laffitte BA, Barak Y, Joseph SB, Liao D, Nagy L, Edwards PA, Curtiss LK, Evans RM, Tontonoz P. 
A PPAR gamma-LXR-ABCA1 pathway inmacrophages is involved in cholesterol efflux and atherogenesis. Mol Cell, 2001; 7:161-71.

Cimmino G, Ibanez B, Vilahur G, Speidl WS, Fuster V, Badimon L, Badimon JJ. Up-regulation of reverse cholesterol transport key players and rescue from global inflammation by ApoA-I (Milano). J Cell Mol Med, 2009; 13:3226-35.

El Bouhassani M, Gilibert S, Moreau M, Saint-Charles F, Treguier M, Poti F, Chapman MJ, Le Goff W, Lesnik P, Huby T. Cholesteryl ester transfer protein expression partially attenuates the adverse effects of SR-BI receptor deficiency on cholesterol metabolism and atherosclerosis. J Biol Chem, 2011; 286:17227-38.

Geyeregger R, Zeyda M, Stulnig TM. Liver X reseptor in cardiovascular and metabolic disease review. Cell Mol Life Sci, 2006; 63:524-39.

Hosomi R, Fukunaga K, Arai H, Kanda S, Nishiyama T, Yoshida M. Effect of dietary protamine on lipid metabolism in rats. Nutr Res Pract, 2010; 4(6):462-9.

Hu YW, Wang Q, Ma X, Li XX, Liu XH, Xiao J, Liao DF, Xiang J, Tang CK. TGF-beta1 up-regulates expression of $A B C A 1$, ABCG1 and SR-BI through Liver X Receptor signaling pathway in THP-1 macrophage derived foem cells. J Atheroscler Thromb, 2010; 17(5):493-502.

Julve J, Llaverias G, Blanco-Vaca F, Escola-Gil JC. Seeking novel targets for improving in vivo macrophage-specific reverse cholesterol transport: translating basic science into new therapies for the prevention and treatment of atherosclerosis. Curr Vasc Pharmacol, 2011; 9:220-37.

Kouadjo K, Nishida Y, Cadrin-Girard JF, Yoshioka M, St-Amand J. Housekeeping and tissue-specific genes in mouse tissues. BMC Genom, $2007 ; 8: 127$.

Lizuka M, Ayaori M, Uto-Kondo H, Yakushiji E, Takiguchi S, Nakaya K. Astaxanthin enhances ATP-binding cassette transporter A1/G1 expressions and cholesterol efflux from macrophages. J Nutr Sci Vitaminol, 2012; 58(2):96-04.

Maitra U, Li L. Molecular mechanisms responsible for the reduced expression of cholesterol transporters from macrophages by lowdose endotoxin. Aterioscler Thromb Vasc Biol, 2013; 33(1):24-33.

Meyer J, Graf GA, Westhuyzen D. New developments in selective cholesteryl ester uptake. Curr Opin Lipidol, 2013; 24(5):386-92.

Murwani S, Ali M, Muliartha K. Diet aterogenik pada tikus putih (Rattus novergicus strain wistar) sebagai model hewan aterosklerosis Jurnal Kedokteran Brawijaya, 2006; XXII(1).

Ogura M, Ayaori M, Terao Y, Hisada T, Iizuka M, Takiguchi S, Uto-Kondo H, Yakushiji E, Nakaya K, Sasaki M, Komatsu T, Ozasa $\mathrm{H}$, Ohsuzu F, Ikewaki K. Proteasomal inhibition promotes ATP-binding cassette transporter A1 (ABCA1) and ABCG1 expression and cholesterol efflux from macrophages in vitro and in vivo. Arterioscler Thromb Vasc Biol, 2011; 31(9):1980-7.

Palozza P, Simone R, Catalano A, Parrone N, Monego G, Ranelletti FO. Lycopene regulation of cholesterol synthesis and efflux in human macrophages. J Nutr Biochem, 2011; 22(10):971-8.
Rader DJ, Alexander ET, Weibel GL, Billheimer J, Rothblat GH. The role of reverse cholesterol transport in animals and humans and relationship to atherosclerosis. J Lipid Res Suppl, 2009; 50(Suppl): S189-94.

Rosenblat M, Volkova N, Coleman R, Almagor Y, Aviram M. Antiatherogenicity of extra virgin olive oil and its enrichment with green tea polyphenols in the atherosclerotic apolipoprotein-E-deficient mice: enhanced macrophage cholesterol efflux. J Nutr Biochem, 2008; 19(8): $514-23$.

Uto-Kondo H, Ayaori M, Nakaya K, Takiguchi S, Yakushiji E, Ogura M, Terao Y, Ozasa H, Sasaki M, Komatsu T, Sotherden GM, Hosoai T, Sakurada M, Ikewaki K. Citrulline increases cholesterol efflux from macrophages in vitro and ex vivo via ATP-binding cassette transporters. J Clin Biochem Nutr, 2014; 55(1):32-9.

Uto-Kondo H, Ayaori M, Ogura M, Nakaya K, Ito M, Suzuki A, Takiguchi SI, Yakushiji, Hisada T, Sasaki M, Ohsuzu F, Ikewaki K. Coffee consumption enhances highdensity lipoprotein-mediated cholesterol efflux in macrophages. Circ Res, 2010; 106(4):779-87

Voloshyna I, Hai O. Resveratrol mediates anti-atherogenic effects on cholesterol flux in human macrophages and endothelium via PPAR gamma and adenosine. Pharmacol, 2013; 698(1-3):299-309.

Wojcicka G, Wisniewska AJ, Horoszewicz K, Beltowski J. Liver $\mathrm{X}$ receptors (LXRs) part 1: structure, function, regulation of activity and role in lipid metabolism. Postepy Hig med Dosw, 2007; 61:736-59.

Zhang Y, Brevoort SR, Angdisen J. Liver LXR $\alpha$ expression is crucial for whole body cholesterol homeostasis and reverse cholesterol transport in mice. J Clin Invest, 2010; 122(5):1688-700.

Zhang Y, Da Silva JR, Reilly M, Billheimer JT, Rothblat GH, Rader DJ. Hepaticexpression of scavenger receptor class B type I (SR-BI) is a positive regulator of macrophage reverse cholesterol transport in vivo. J Clin Invest, 2005; 115:2870-4.

Zhao JF, Ching LC, Huang YC, Chen CY, Chiang AN, Kou YR, Shyue SK, Lee TS. Molecular mechanism of curcumin on the suppression of cholesterol accumulation in macrophage foam cells and atherosclerosis. Mol Nutr Food Res, 2012; 56(5):691-701.

Zhao Y, Pennings M, Vrins CL, Calpe-Berdiel L. Hypocholesterolemia, foam cell accumulation, but no atherosclerosis in mice lacking $\mathrm{ABC}$-transporter $\mathrm{A} 1$ and scavenger receptor $\mathrm{BI}$. Atherosclerosis, $2011 ; 218: 314-22$

How to cite this article:

Susanti E, Ratnawati R, Aulanni'am A, Rudijanto A. Catechins green tea upregulates the expression of ABCA1, ABCG1, and SRB1 in rats induced atherogenic diet. J Appl Pharm Sci, 2019; 9(03):091-097. 